\title{
Implementasi Pendidikan Kebencanaan di Indonesia (Sebuah Studi Pustaka tentang Problematika dan Solusinya)
}

\author{
Lilik Tahmidaten $^{1]}$, Wawan Krismanto ${ }^{2]}$ \\ ${ }^{11}$ Kementerian Pendidikan \& Kebudayaan RI \\ ${ }^{2]}$ Universitas Negeri Makassar \\ E-mail: ${ }^{1]}$ lilik.tahmidaten@ kemdikbud.go.id
}

\begin{abstract}
Abstrak
Secara geografis Indonesia termasuk suatu negara yang berpotensi sekaligus rawan bencana seperti letusan gunung berapi, gempa bumi, tsunami, banjir dan tanah longsor. Untuk itu kesadaran akan potensi bencana menjadi hal yang sangat penting bagi setiap warga negara Indonesia. Hasil penelitian studi pustaka ini menunjukkan bahwa pendidikan menjadi sarana yang strategis untuk mengenalkan potensi bencana dan resikonya kepada setiap peserta didik, sehingga kelak menjadi warga negara yang sadar akan bencana alam. Pendidikan risiko atas bencana alam atau lebih populer dengan pendidikan kebencanaan (disaster education) atau pendidikan resiko kebencanaan (disaster risk education) adalah proses membangun kesadaran yang dimulai dari membangun pengetahuan, pemahaman dan tindakan yang mendorong kesiapsiagaan, pencegahan dan pemulihan. Dalam menghadapi kondisi alam saat ini, baik secara individu maupun masyarakat, manusia harus belajar hidup dengan alam, bukan mencoba mengendalikannya, sehingga memerlukan upaya mitigasi yang fokusnya berupaya menghindari dan meminimalisir bahaya melalui berbagai rekayasa teknologi. Namun demikian akan lebih tepat jika mitigasi dimulai dari perubahan perilaku manusia itu sendiri dalam menghadapi bahaya bencana alam. Membahas hal ini maka pendidikan kebencanaan menjadi mutlak diperlukan sebab pendidikan dianggap efektif mampu merubah perilaku dan perubahan perilaku cenderung jauh lebih murah dan lebih permanen daripada rekayasa teknologi semata. Oleh karena itu itu perlu langkah strategis guna: 1) Menata kembali sistem pendidikan kebencanaan yang jelas, terstruktur dan sistematis, 2) Menata kembali peran yang jelas dan tegas diantara kementerian dan lembaga-lembaga terkait dengan kebencanaan, 3) Menyusun kembali kurikulum kebencanaan (disaster curriculum) dan 4) Melakukan sosialisasi dan edukasi tentang sistem dan kurikulum pendidikan kebencanaan yang terstruktur, konsisten dan berkelanjutan.
\end{abstract}

Kata Kunci: Pendidikan kebencanaan, Kurikulum kebencanaan, Pendidikan resiko kebencanaan 


\title{
Disaster Education Implementation in Indonesia (A Literatur Study on Problematics and Solutions)
}

\begin{abstract}
In accordance with geographical location, Indonesia is one of the potential and disaster-prone countries such as volcanic eruptions, earthquakes, tsunamis, floods and landslides. For this reason, awareness of potential disasters is very important for every Indonesian citizen. The results of this literature study show that education is a strategic tool for introducing potential disasters and the risks to each student, so that later they become citizens who are aware of natural disasters. Risk education for natural disasters or more popular with disaster education or disaster risk education is a process of building awareness that starts from building knowledge, understanding and actions that encourage preparedness, prevention and recovery. In facing current natural conditions, both individually and society, humans must learn to live with nature, not try to control it, so that it requires mitigation efforts whose focus is trying to avoid and minimize hazards through various engineering technologies. However, it would be more appropriate if mitigation starts from changes in human behavior itself in the face of natural disaster hazards. Discussing this, disaster education is absolutely necessary because education is considered effective in being able to change behavior and behavior change tends to be much cheaper and more permanent than technological engineering. Therefore it is necessary to take strategic steps to: 1) Rearrange a clear, structured and systematic disaster education system, 2) Reorganize the clear and decisive role between ministries and institutions related to disaster, 3) Re-arrange disaster curricula (disaster curriculum) and 4) Conduct socialization and education of structured, consistent and sustainable disaster education systems and disaster curriculum.
\end{abstract}

Keywords: Disaster education, Disaster curriculum, Disaster risk education

\section{PENDAHULUAN}

Sebagai negara kepulauan Wilayah Indonesia terdiri dari pulaupulau posisi berada diantara dua samudera (Hindia-Pacifik). Selain itu Indonesia dilalui oleh empat lempengan bumi sehingga dipermukaan datarannya terdapat banyak gunung berapi aktif. Berdasarkan kondisi geografis tersebut menempatkan Indonesia memiliki potensi bencana yang tinggi. Dalam situsnya, Badan Nasional Penanggulangan Bencana (BNPB) menguraikan lebih lanjut bahwa secara geografis Indonesia merupakan negara kepulauan yang terletak pada pertemuan empat lempeng tektonik yaitu lempeng Benua Asia, Benua Australia, lempeng Samudera Hindia dan Samudera Pasifik. Pada bagian selatan dan timur Indonesia terdapat sabuk vulkanik (volcanic arc) yang memanjang dari Pulau Sumatera, Jawa - Nusa Tenggara, Sulawesi, yang sisinya berupa pegunungan vulkanik tua dan dataran rendah yang sebagian didominasi oleh rawa-rawa. Kondisi tersebut sangat berpotensi sekaligus rawan bencana seperti letusan gunung berapi, gempa bumi, tsunami, banjir dan tanah longsor. Data menunjukkan bahwa Indonesia merupakan salah satu negara yang memiliki tingkat 
kegempaan yang tinggi di dunia, lebih dari 10 kali lipat tingkat kegempaan di Amerika Serikat (BNPB, 2017). Hal ini diperparah dengan kerusakan alam yang terus terjadi sejak puluhan tahun lalu hingga saat ini yang makin menambah resiko terjadinya bencana alam. Fenomena global berupa pemanasan global dan perubahan iklim juga menambah resiko terjadinya bencana alam di Indonesia semakin meningkat. Dalam buku Natural Hazards and Disasters, Donald Hyndman dan David Hyndman menyatakan bahwa perubahan iklim bumi diperkirakan akan menyebabkan terjadinya erosi garis pantai yang terjadi secara cepat, bersamaan dengan itu peristiwa cuaca yang lebih ekstrem menyebabkan terjadinya tanah longsor, banjir, angin topan, dan kebakaran hutan (Hyndman \& Hyndman, 2017).

Sebuah studi yang dilakukan oleh Bündnis Entwicklung Hilft dan Ruhr University Bochum Jerman yang dipublikasikan melalui World Risk Report 2018 menempatkan Indonesia pada urutan ke 39 di dunia dalam hal resiko bencana alam dan tergolong dalam kategori High Risk (Bündnis Entwicklung Hilft, 2018; Heintze et.al, 2018). Sejalan dengan hal tersebut, Data BNPB juga menunjukkan bahwa jumlah kejadian bencana alam semakin meningkat di wilayah Indonesia, bahkan sejak 2009 sudah di atas 1.200 kejadian dan terus meningkat sejak 2016 dengan kejadian lebih dari 2.300 bencana alam dan puncaknya pada tahun 2017 sebanyak 2.869 kejadian. Tahun 2018 terjadi 2.573 bencana alam dengan menelan korban sebanyak 4.814 orang meninggal dunia. Tercatat sejak tahun 2000 telah terjadi 25.109 kejadian bencana alam dengan merenggut nyawa 189.493 orang dan 372,568 orang menderita luka-luka (BNPB, 2019). Tiga kejadian bencana alam besar terakhir yang sangat memilukan diantaranya adalah Gempa, tsunami dan likuifaksi di Donggala dan Palu, tsunami akibat aktivitas gunung anak krakatau di Banten dan Lampung dan banjir bandang di Papua yang semuanya itu menelan korban jiwa dan kerugian yang tidak sedikit.

Terjadinya bencana alam sering dikaitkan dengan isu perubahan iklim di bumi dengan isu populernya adalah pemanasan global dan kerusakan lingkungan yang mendorong peningkatan terjadinya bencana alam. Isu tersebut memang kian gencar dibahas dan dikaji seiring dengan pembuktian-pembuktian fenomena bencana alam yang terjadi, termasuk di Indonesia. Apalagi jika melihat data BNPB tentang meningkatnya kejadian bencana alam dan korban jiwa seperti yang diuraikan di atas, seharusnya menjadi perhatian pemerintah dan masyarakat Indonesia. Perhatiannya tidak sebatas tanggap pada isu pemanasan global yang mendunia, tapi justru kesiap-siagaannya menghadapi bencana alam yang terjadi sebagai akibat dari pemanasan global dan kerusakan lingkungan. Bahkan dalam hal ini banyak pakar internasional dari luar negeri yang telah memperingatkan Indonesia untuk lebih sadar potensi bencana yang akan terjadi (CNN, 2018). Bahkan ahli lain menyatakan Indonesia tidak memiliki "safety culture" dalam terkait bencana (Kompas.com, 2018). Untuk itu kesadaran akan potensi bencana menjadi hal yang sangat penting bagi setiap masyarakat di negara-negara yang memiliki high risk seperti Indonesia, dengan demikian korban bencana alam dapat ditekan seminimal mungkin. Namun demikian tidaklah mudah untuk membangun kesadaran ini. Banyak pihak yang harus dirangkul untuk membangun kesadaran ini, salah satunya adalah pihak-pihak 
yang berkecimpung dalam dunia pendidikan untuk berkontribusi.

Pendidikan menjadi sarana yang strategis untuk mengenalkan potensi bencana dan resikonya kepada setiap peserta didik, sehingga kelak menjadi warga negara yang sadar akan bencana alam. Pendidikan risiko atas bencana alam atau lebih populer dengan pendidikan kebencanaan (disaster education) atau pendidikan resiko kebencanaan (disaster risk education) adalah proses membangun kesadaran yang dimulai dari membangun pengetahuan, pemahaman dan tindakan yang mendorong kesiapsiagaan, pencegahan dan pemulihan. Dalam hal ini pendidikan risiko mengacu pada proses yang dimulai dari membangun pengetahuan tentang lingkungan, pemahaman tentang fenomena alam dan resikonya sehingga dapat memperhitungkan tindakan dan perilaku dalam keadaan darurat bencana. Oleh karena itu, pendidikan risiko merupakan proses sosialisasi, pemahaman sains (fenoemana alam) serta pengembangan keterampilan menuju keselamatan, yang disertai dengan membangun kesadaran atas bencana alam (Musacchio et al., 2016). Dalam hal ini Donald Hyndman dan David Hyndman mengungkapkan bahwa baik menghadapi kondisi alam saat ini, baik secara individu maupun masyarakat, manusia harus belajar hidup dengan alam, bukan mencoba mengendalikannya, sehingga memerlukan upaya mitigasi yang fokusnya berupaya menghindari dan meminimalisir bahaya melalui berbagai rekayasa teknologi. namun demikian akan lebih tepat jika mitigasi dimulai dari perubahan perilaku manusia itu sendiri dalam menghadapi bahaya bencana alam dan berbicara hal ini maka pendidikan kebencanaan menjadi mutlak diperlukan. Perubahan perilaku cenderung jauh lebih murah dan lebih permanen daripada rekayasa teknologi (Hyndman \& Hyndman, 2017).

Bagaimana dengan di Indonesia? Pendidikan di Indonesia sampai saat ini, belum ada tindakan yang sistematis dan konkrit untuk memasukkan muatan kebencanaan ke dalam kurikulum sekolah, sebab yang nampak adalah muatan pendidikan kebencanaan masih sebatas isu yang berkembang disaat terjadi bencana alam besar yang menjadi pusat perhatian pemerintah dan masyarakat. Setelah bencana berlalu maka isu muatan kebencanaan ke dalam kurikulum pendidikan tersebut ikut-ikutan berlalu pula tanpa ada progres yang signifikan, terutama implementasinya di sekolahsekolah. Meskipun secara master plan dan dokumen-dokumen yang terkait telah disusun dan disiapkan oleh otoritas tertakit dalam hal ini Kementerian Pendidikan dan Kebudayaan dan lembaga/kementerian lain yang terkait dengan urusan kebencanaan di Indonesia, namun sekali lagi implementasi pada sekolah-sekolah masih rendah dan terkesan sebatas seremonial belaka. Untuk itu pada penelitian studi pustaka ini berusaha menjawab beberapa rumusan masalah: 1) bagaimanakah konsep pendidikan kebencanaan (disaster education)?, 2) Seperti apa konsep pendidikan kebencanaan (disaster education) di berbagai negara?, 3) Bagaimana pendidikan kebencanaan (disaster education) dan problematika implementasinya di Indonesia? dan 4) Bagaimana solusi atas problematika implementasi pendidikan kebencanaan (disaster education) di Indonesia?

\section{METODE}

Penelitian ini merupakan penelitian kualitatif yang bersifat studi pustaka (library research) dengan menggunakan sumber data berupa 
buku-buku referensi dan artikel-artikel jurnal ilmiah. Pada penelitian ini rangkaian kegiatannya berkenanaan dengan pengumpulan data pustaka, membaca dan mencatat, lalu mengolah informasi yang sesuai dan diperlukan untuk menjawab rumusan masalah yang akan dipecahkan. Adapun prosedur yang dilakukan pada penelitian studi pusataka ini meliputi: 1) menggali ide umum tentang penelitian, 2) mencari informasi yang mendukung topik penelitian, 3) mempertegas fokus penelitian dan mengorganisasi bahan yang sesuai, 4) Mencari dan menemukan sumber data berupa sumber pustaka utama yaitu buku dan artikelartikel jurnal ilmiah, 5) melakukan reorganisasi bahan dan catatan simpulan yang didapat dari sumber data, 6) melakukan review atas informasi yang telah dianalisis dan sesuai untuk membahas dan menjawab rumusan masalah penelitian, 7) memperkaya sumber data untuk memperkuat analisis data dan 8) menyusun hasil penelitian.

\section{HASIL DAN PEMBAHASAN a. Konsep Pendidikan Kebencanaan}

Pendidikan kebencanaan atau kesiapsiagaan bencana dapat dapat dikatakan sebagai konsep yang mengintegrasikan pencegahan bencana ke dalam kurikulum pendidikan di sekolah, mulai dari usia dini, sekolah dasar hingga universitas. Kesiapsiagaan ini ditujukan untuk mengurangi resiko bencana. Dalam hal ini Winarni \& Purwandari menjelaskan bahwa pengurangan risiko bencana (PRB) merupakan serangkaian konsep dan kegiatan yang bertujuan untuk mengurangi risiko bencana melalui kegiatan sistematis dan untuk menganalisis dan mengelola dampak buruk bencana. Kerangka kerja pengurangan bencana, kesadaran dan kewaspadaan, sikap preventif dan kuratif perlu dipupuk dan diinternalisasi untuk menjadi nilai-nilai budaya dalam suatu komunitas. Pengurangan risiko bencana (PRB) di sekolah-sekolah bertujuan untuk memelihara: (1) nilainilai dan sikap manusia terhadap risiko bencana; (2) pemahaman risiko bencana; (3) pengetahuan dan keterampilan untuk pencegahan bencana baik secara individu maupun masyarakat; dan (4) kemampuan tanggap darurat (Winarni \& Purwandari, 2018). Nifa dkk. mengungkapkan bahwa meningkatkan pendidikan kebencanaan di sekolah merupakan hal yang penting mengingat: 1) anak-anak adalah salah satu bagian masyarakat yang paling rentan selama bencana; 2) mereka mewakili masa depan; 3) sekolah berfungsi sebagai lokasi pusat komunitas untuk pertemuan dan kegiatan kelompok; dan 4) efek pendidikan dapat ditransfer ke orang tua dan masyarakat (Nifa, Abbas, Lin, \& Othman, 2017). Dengan demikian, sekolah dianggap memainkan peran penting dalam meningkatkan perhatian dan kesadaran di kalangan siswa, guru, dan orang tua serta dalam masyarakat setempat tentang potensi dan resiko kebencanaan di lingkungannya. Meningkatkan perhatian dan kesadaran itulah yang diharapkan akan mampu mengurangi resiko dari bencana alam yang mungkin akan menimpanya sewaktu-waktu.

Program pendidikan kebencanaan cenderung menekankan pada pengetahuan, keterampilan, dan perilaku pribadi dan sosial untuk mengurangi risiko dan meningkatkan ketahanan, baik secara fisik maupun psikososial ketika terjadi sebuah bencana alam. Ronan dkk. menjelaskan bahwa tujuan utama dari pendidikan kebencanaan adalah untuk mengurangi risiko dalam kaitannya dengan 
peristiwa-peristiwa berbahaya dengan membantu anak-anak dan keluarga untuk belajar strategi-strategi pengurangan risiko dan kerentanan. Dengan kata lain, tujuannya adalah untuk mengurangi risiko dan meningkatkan ketahanan terhadap dampak fisik dan psikososial dari bencana (Ronan, Alisic, Towers,
Johnson, \& Johnston, 2015). Adapun output yang diharapkan dari pendidikan kebencanaan ini adalah siswa (anakanak) memiliki literasi kebencanaan (Chung \& Yen, 2016), dalam hal ini Chung \& Yen mengidentifikasi indikator literasi kebencanaan yang dilihat pada Tabel 1 berikut ini.

Tabel 1. Indikator Literasi Kebencanaan sebagai Output Pendidikan Kebencanaan

\begin{tabular}{|c|}
\hline \multirow{2}{*}{$\begin{array}{l}\text { Dimension Category } \\
\text { Knowledge }\end{array}$} \\
\hline \\
\hline Disaster knowledge \\
\hline Synthesize and analyze the definitions and causes of various disasters \\
\hline Explain the impacts and harms of disasters to humans and their environment \\
\hline Preparedness knowledge \\
\hline Develop the disaster mitigation procedures \\
\hline Make the action plan of disaster mitigation and preparedness \\
\hline Response knowledge \\
\hline Decide the response procedures in the event of a disaster \\
\hline Design the measures of post-disaster rescues and medical cares \\
\hline Attitude \\
\hline Prevention awareness \\
\hline Evaluate the environment comprehensively and recognize the potential hazards \\
\hline Synthesize and analyze the disaster-related information proactively \\
\hline Prevention values \\
\hline Promote the importance of disaster prevention, disaster relief, and evacuation plan \\
\hline Explain the relation between disaster prevention and social cost \\
\hline Prevention sense of responsibility \\
\hline $\begin{array}{l}\text { Organize the promotion of campus and community disaster prevention } \\
\text { Plan the execution of campus evacuation and shelter placement }\end{array}$ \\
\hline Plan the execution of campus evacuation and shelter placement \\
\hline e \\
\hline Preparedness action \\
\hline \multirow{2}{*}{$\begin{array}{l}\text { Plan the escape routes and sites in the event of a disaster } \\
\text { Plan and particinate in the drills and training for disaster prevention and relief }\end{array}$} \\
\hline \\
\hline Response behaviors \\
\hline Ensure self-safety and help others to escape in the event of a disaster \\
\hline Cooperate during the evacuation and shelter placement \\
\hline
\end{tabular}

Sumber: (Chung \& Yen, 2016)

Selain itu ada lima dimensi kunci dalam pendidikan kebencanaan, yang masing-masing dapat dimasukkan dalam kurikulum kebencanaan (disaster curriculum), yaitu: 1) memahami sains dan mekanisme bencana alam, 2) mempelajari dan mempraktikkan langkah-langkah dan prosedur keselamatan, 3) memahami faktor pendorong risiko dan bagaimana bahaya kecil dan sederhana dapat menjadi bencana, 4) membangun kapasitas pengurangan risiko masyarakat dan 5) membangun budaya keselamatan dan ketahanan kelembagaan dan komunitas secara luas (Kagawa \& Selby, 2014). 
Melalui pengenalan, pemahaman, penyadaran dan pembiasaan terkait ancaman bahaya dan bencana alam di sekolah maka diharapkan siswa akan menjadi warga masyarakat yang sadar dan refleks atas terjadinya bencana yang mengancam bahkan disaat waktu-waktu yang tidak diprediksi atau tanpa ada peringatan sekalipun. Genta Nakano dalam chapter book nya menegaskan bahwa sekolah memainkan peran penting dalam mentransfer pengetahuan dalam resiko kebencanaan karena sekolah adalah pusat pendidikan dan dapat menyebarkan pengetahuan melalui siswa, orang tua dan masyarakat. Dengan membekali hal tersebut, maka sekolah membina orangorang dengan pengetahuan dan keterampilan untuk melindungi hidup mereka sendiri dari bencana sebagai tujuan dasar dari pendidikan kebencabaan. Pendidikan kebencanaan di sekolah harus mengajarkan berbagai hal tentang kebencanaan, tidak hanya bahaya alam tetapi juga interaksi manusia dengan lingkungan alam, mengajarkan dampak kegiatan intervensi manusia terhadap lingkungan seperti eksploitasi sumber daya alam dan pola pemukiman manusia. Selain itu mengajarkan pula berbagai keterampilan tentang apa yang harus dilakukan ketika bencana terjadi (Shiwaku, Sakurai, \& Shaw, 2016).

\section{b. Pendidikan Kebencanaan Di Berbagai Negara}

Kagawa dan Selby melakukan sebuah studi tentang pendidikan kebencanaan pada kurikulum sekolah atau mereka menggunakan istilah disaster risk reduction in the school curriculum atau Pendidikan Risiko Bencana (PRB) pada kurikulum sekolah di 4 negara yaitu Bangladesh, Kamboja, Pakistan \& Indonesia, hasil studinya menyimpulkan beberapa sintesis berikut (Kagawa \& Selby, 2014).

\section{1) Pengembangan Kurikulum PRB di Bangladesh}

- PRB telah diintegrasikan dalam buku pelajaran sekolah di Banglasedh. Namun karena akses siswa untuk mempelajari lebih lanjut kurikulum PRB mengalami permasalahan sebab tingkat putus sekolah yang tinggi dan signifikan terjadi di Bangladesh terutama setelah kelas 5.

- Guru-guru di Bangladesh masih belum memahami sepenuhnya kurikulum PRB, hal ini terkait terkait kurangnya pelatihan PRB

- Tidak adanya integrasi PRB ke dalam lintas-kurikuler (lintas bidang studi) dan kemajuan penanaman nilai-nilai dalam pembelajaran PRB dan hasil belajarnya masih rendah.

- Pembelajaran PRB yang ada di Bangladesh masih berfokus pada fakta dan menghafal, bukan keterampilan atau sikap.

- Meskipun tersedia beberapa bahan pembelajaran aktif yang sangat baik, namun proses pembelajaran yang menonjol adalah pengajaran gaya frontal (ceramah)

- Pendekatan kurikulum yang terpusat menyebabkan pandangan 'satu teks cocok untuk semua' sehingga terkesan kurang disesuaikan untuk memenuhi keanekaragaman bahaya di berbagai bagian negara Bangladesh.

- Sementara ini ada beberapa proyek yang sangat baik berbasis contoh keterlibatan siswa dalam prakarsa membangun sekolah yang aman dan ketahanan / sekolah misal oleh lembagalembaga pembangunan. Namun 
demikian sejauh ini, keterlibatan tersebut belum secara sistematis tertanam dalam kurikulum sekolah-sekolah formal di Bangladesh.

- Peningkatan kapasitas guru secara insidental dalam memfasilitasi kurikulum PRB sudah ada, namun tidak ada penyediaan pelatihan PRB sistematis dan berkelanjutan bagi guru-guru di Bangladesh.

\section{2) Pengembangan Kurikulum PRB di Kamboja}

- Kerangka kebijakan menyeluruh untuk pengembangan kurikulum PRB telah diterapkan di Kamboja.

- PRB telah diutamakan dalam kurikulum Geografi dan Studi Bumi pada tingkat 8, namun beberapa wilayah Kamboja banyak siswa yang cenderung drop-out keluar dari sekolah sebelum tingkat 8 sehingga tidak menerima pendidikan PRB

- Telah ada serangkaian proyek pengembangan kurikulum inovatif yang menjangkau sejumlah sekolah di Kamboja.

- Telah ada pedoman sekolah aman, anggaran yang baik, langkah nyata, infusi dan pendekatan interdisipliner untuk muatan PRB.

- Sebuah proyek yang didukung oleh MOEYS baru-baru ini menawarkan prospek pengembangan kurikulum PRB berbasis sekolah dan lokal melalui peningkatan kapasitas guru-guru di Kamboja.

- Meskipun ada program berbasis proyek yang unggul tentang contoh-contoh keterlibatan siswa dalam inisiatif pembangunan sekolah yang aman dan ketahanan sekolah / masyarakat, namun sejauh ini, adanya program tersebut belum secara sistematis tertanam dalam kurikulum sekolah formal di Kamboja.

- Sementara peningkatan kapasitas guru hanya ada melalui lembaga inisiatif sekolah ramah anak nasional dan melalui proyek pengembangan kurikulum PRB yang terpisah, sementara tidak ada penyediaan pelatihan PRB yang sistematis.

\section{3) Pengembangan Kurikulum PRB di Pakistan}

- Pengembangan kurikulum Pakistan pada 2014 berada dalam kondisi transisi saat negara ini beralih dari kurikulum nasional dan menuju kurikulum yang didelegasikan pada provinsi (desentralisasi); Hal ini memiliki implikasi yang signifikan untuk peran lembaga-lembaga pembangunan dalam dukungan terhadap kurikulum PRB di Pakistan.

- Pengajaran dan pembelajaran PRB di Pakistan yang sistematis, teratur dan berkelanjutan saat ini masih kurang karena Pendidikan PRB di Pakistan harus menjangkau kantong-kantong atau daerah-daerah yang terisolasi.

- Untuk mengembangkan kurikulum berbingkai PRB di tingkat propinsi, memerlukan dukungan pengembangan kapasitas terutama di provinsiprovinsi yang lebih kurang beruntung (terisolasi) di negara ini akibat konflik internal di Pakistan.

- Ada kebijakan nasional Pakistan yang mendukung integrasi PRB ke dalam kurikulum di semua tingkat

- Kebijakan pendidikan yang berorientasi aksi dari pendidikan PRB telah diwujudkan dalam beberapa dokumen kebijakan 
pemerintah Pakistan, tetapi secara umum aksi nyatanya tidak terwujud dalam praktik di lapangan.

- Setelah terjadi bencana besar sekitar tahun 2014, banyak lembaga pembangunan mulai membangun bekerja sama dengan pemerintah Pakistan untuk mempromosikan pendidikan PRB, meskipun mekanisme koordinasi masih perlu dikembangkan.

- Kesempatan pelatihan guru berbasis proyek dan jangka pendek tentang PRB memang telah ada di Pakistan, namun tidak ada pelatihan PRB yang berkelanjutan pada guru-guru dalam jabatan maupun pra jabatan yang sistematis.

Berdasarkan uraian di atas maka dapat dilihat bahwa pendidikan kebencanaan di 3 negara berkembang yaitu Bangladesh, Kamboja dan Pakistan sudah mulai diintegrasikan dalam kurikulum pendidikan mereka. Hanya saja berbagai persoalan masih mendera mulai pembiayaan, daerah terisolasi, pembekalan pada guru yang berkelanjutan baik pada guru-guru dalam jabatan maupun pra jabatan dan tingkat implementasinya dilapangan. Kebijakan tentang pendidikan kebencanaan di 3 negara tersebut juga sudah ada dan dikuatkan dengan adanya dokumen-dokumen pendidikan kebencanaan, namun menurut studi Fumiyo Kagawa dan David Selby, secara umum aksi nyatanya tidak terwujud dalam praktik di lapangan atau sekolah-sekolah di 3 negara berkembang tersebut.

\section{4) Pendidikan Kebencanaan di Selandia Baru}

Studi lain tentang kesiapan menghadapi bencana dilakukan oleh Kaori Kitagawa dkk. yang mengilustrasikan persiapan kebencanaan di negara Selandia Baru (Kitagawa, Preston, \& Chadderton, 2017). Meskipun studinya fokus membahas tentang infrastruktur yang mendukung kesiapan dalam menghadapi bencana, namun ada beberapa hal yang mereka juga mengkaitkan dengan pendidikan kebencanaan. Adapun sintesis studi tersebut dapat diuraikan sebagai berikut. Selandia Baru (New Zeland/NZ) merupakan salah satu negara yang sangat rentan terhadap bencana alam. Potensi bencana gempa bumi yang dimilikinya berpotensi menghancurkan wilayah yang luas seperti yang melanda wilayah Canterbury pada Februari 2011. Pemerintah NZ telah lama menyadari perlunya mengambil pendekatan terstruktur dan terkoordinasi untuk melindungi infrastruktur nasional dan memperkuat ketahanan di semua tingkatan (sosial, politik, ekonomi), dan pendekatan yang diambil dianggap sangat inovatif. Sejak pertengahan 1990-an, sebagai reaksi atas pengamatan serangkaian bencana internasional, NZ mulai bergerak dari pendekatan reaksioner dan menuju pendekatan yang proaktif. Kementerian Pertahanan Sipil dan Manajemen Darurat (MCDEM: Ministry of Civil Defence and Emergency Management) dibentuk dengan tujuan untuk mengelompokkan semua ancaman bersama-sama, dan memfokuskan pada respons daripada bahaya. Strategi Nasional CDEM (Civil Defence and Emergency Management) menetapkan visi Resilient New Zealand atau Selandia Baru Tangguh. MCDEM fokus pada apa yang mereka sebut sebagai 4 'R': Reduction, Readiness, Response, Recovery atau Pengurangan risiko, Kesiapan, Respon, Pemulihan. Organisasi CDEM dibangun di tiga tingkatan: lokal, regional dan nasional. 
Selain membangun organisasi pengelola kebencanaan, NZ juga fokus pada pendekatan yang terintegrasi dalam pendidikan untuk bencana. Pendidikan bencana dikelola dan dipimpin juga oleh MCDEM. Mereka memimpin kampanye penyadaran publik untuk memperkuat pesan kesiapsiagaan. Mereka juga mendesain bahan ajar untuk sekolah formal di semua tingkatan. Sementara tugas Kementerian Pendidikan memastikan bahwa setiap sekolah menerima bahan ajar tersebut. Selain itu, pendidikan kesiapsiagaan bencana juga dilakukan oleh badan lain. Sebagai contoh, Komisi Gempa Bumi, sebuah lembaga asuransi milik negara yang menyediakan asuransi bencana untuk bencana geologi yang meliputi bangunan, isi dan tanah, juga melakukan penelitian dan kegiatan pendidikan dengan retribusi. Mereka berperan sebagai lembaga yang menyatukan para profesional dan akademisi. Mereka berkontribusi pada kegiatan pendidikan kesiapsiagaan bencana seperti mendanai kunjungan lapangan untuk sekolah dan kampanye kesadaran masyarakat yang bertujuan meminimalkan kerusakan bagi rumah tangga; mendukung beasiswa universitas baik dalam ilmu geologi dan sosial; memberikan hibah untuk postdocs; melakukan proyek kolaborasi dengan pihak berwenang setempat; dan bekerja secara kolaboratif dengan pemerintah untuk mengidentifikasi tema penelitian.

Dari studi Kaori Kitagawa dkk. di atas dapat menggambarkan bahwa di $\mathrm{NZ}$, perlindungan dan ketahanan terhadap bencana dari sisi kesiapsiagaan organisasi dan infrastruktur menjadi prioritas utama dalam agenda politik dan ekonomi pemerintahannya, tetapi ada kesenjangan dan sedikit abai dalam hal pendekatan pemerintahan negara NZ terutama dalam hal implementasi kurikulum pendidikan kesiapsiagaan bencana pada pendidikan formal di seluruh wilayah NZ secara berkelanjutan.

\section{5) Konsep Pendidikan Kebencanaan di Jepang}

Salah satu negara lainnya yang memiliki sejarah panjang tentang bencana alam adalah negara Jepang, sebab Jepang memiliki potensi bencana yang sangat tinggi terutama gempa bumi dan tsunami. Bencana alam besar terakhir di tahun 2011 yaitu gempa 9,0 magnitudo yang kemudian menimbulkan tsunami pesisir timur laut Jepang dan menyebabkan 19 ribu orang tewas atau hilang. Sadar dan pengalaman akan dahsyatnya bencana alam yang pernah terjadi dan potensi besar terjadi kembali di waktu yang akan datang, Jepang telah mengembangkan sistem kesiapsiagaan bencana yang baik, termasuk dalam sistem pendidikan kebencanaannya atau di Jepang dikenal sebagai disaster education (DE). Integrasi pendidikan kebencanaan pada sistem pendidikan di Jepang telah mengalami sejarah panjang seiring dengan frekuensi bencana alam yang tinggi terjadi di seluruh wilayah Jepang. Pada sebuah chapter book-nya yang berjudul Continuity and change in disaster education in Japan, Kaori Kitagawa merangkum sejarah panjang tersebut paling tidak pasca perang dunia, rangkuman sejarah tesebut dapat dilihat pada tabel berikut (Kitagawa, 2015). 
Tabel 2. Sejarah Panjang Perkembangan Disaster Education (DE) di Jepang

\begin{tabular}{|c|c|c|}
\hline $\begin{array}{l}\text { Period and influential } \\
\text { disaster }\end{array}$ & Wider contexts & Characteristics of disaster education \\
\hline 1945-1951 & $\begin{array}{l}\text { GHQ instruction based on } \\
\text { democratic and experiential } \\
\text { values }\end{array}$ & $\begin{array}{l}\text { DE rich in its contents and a good } \\
\text { balance between scientific knowledge } \\
\text { and life skills }\end{array}$ \\
\hline \multirow{2}{*}{$\begin{array}{l}\text { A number of disasters } \\
1951-1959\end{array}$} & & \\
\hline & $\begin{array}{l}\text { Start of high economic } \\
\text { growth }\end{array}$ & $\begin{array}{l}\text { Towards scientific understanding of } \\
\text { DE } \\
\text { Scientific knowledge model }\end{array}$ \\
\hline 1959-1977 & High economic growth & $\begin{array}{l}\text { DE undermined by cramming } \\
\text { education }\end{array}$ \\
\hline Ise Bay Typhoon & $\begin{array}{l}\text { Advancement of science and } \\
\text { technology }\end{array}$ & Scientific knowledge model \\
\hline \multirow[t]{2}{*}{$1977-1995$} & $\begin{array}{l}\text { Recognition of societal } \\
\text { problems derived from } \\
\text { cramming education }\end{array}$ & $\begin{array}{l}\text { Potential for } \mathrm{DE} \text { as life skills through } \\
\text { relaxed education }\end{array}$ \\
\hline & $\begin{array}{l}\text { Beginning of relaxed } \\
\text { education }\end{array}$ & Scientific knowledge model \\
\hline 1995-2001 & $\begin{array}{l}\text { Impact on various aspects of } \\
\text { society }\end{array}$ & Revision of DE \\
\hline Hanshin earthquake & $\begin{array}{l}\text { Emergence of civil society } \\
\text { movements }\end{array}$ & $\begin{array}{l}\text { DE as life skills promoted through } \\
\text { relaxed education } \\
\text { Civic participation model }\end{array}$ \\
\hline 2001-2011 & $\begin{array}{l}\text { Emphasis shifted towards } \\
\text { safety }\end{array}$ & $\begin{array}{l}\text { Reorganisation of Safety Education } \\
\text { as a multi-hazard subject }\end{array}$ \\
\hline \multirow{2}{*}{$\begin{array}{l}\text { Ikeda School incident } \\
2011-\end{array}$} & & Multi-hazard model \\
\hline & $\begin{array}{l}\text { Building national resilience } \\
\text { by 'all Japan' }\end{array}$ & $\begin{array}{l}\text { Towards embeddedness of DE in } \\
\text { everyday life }\end{array}$ \\
\hline \multirow{2}{*}{$\begin{array}{l}\text { Tohoku earthquake } \\
\text { and tsunami }\end{array}$} & & Collaborative preparedness \\
\hline & & Everyday model \\
\hline
\end{tabular}

Sumber: (Kitagawa, 2015)

Sejak 2011, Jepang telah mencari DE yang lebih efektif yaitu model kehidupan sehari-hari, yang juga disebut sebagai model 'hidup bersama (kyozon)'. Konsep ini lebih dari sekedar konsep DE sebelumnya yaitu 'kyojo' yang intinya masyarakat Jepang harus 'saling membantu'. Konsep 'kyozon' berasal dari anggapan bahwa masyarakat Jepang sehari-harinya hidup dengan bencana alam, misal di Tokyo Metropolitan yang dikatakan familiar dengan terjadinya gempa besar, atau di Prefektur Kagoshima di mana gunung berapi aktif (Gunung Sakurajima) berada yang sewaktu-waktu dapat mengancam penduduknya. Dalam hal ini, bencana tidak lagi dianggap sebagai 'darurat' sehingga masyarakatnya harus "saling membantu (kyojo)" namun sudah menjadi keseharian sehingga seluruh warganya harus mampu "hidup bersama (kyozon)" dengan bencana alam. Konsep kyojo dan kyozon telah dikembangkan di Jepang sebagai konsep pendidikan DE, argumennya adalah bahwa konsep-konsep tersebut telah menjadi pusat kebijakan bencana pemerintahan Jepang. Misalnya Katada, yang mengajar siswa sekolah Kamaishi mengajarkan keterampilan hidup yang penting untuk bertahan hidup dari tsunami dan nenanamkan konsep kyozon.

Pendidikan DE di Jepang di usia dini tidak di awali dari konsep-konsep bencana alam yang mungkin dapat menanamkan ketakutan pada siswanya, namun harus dimulai dari cerita-cerita tentang alam yang memberi manfaat, misalnya DE harus dimulai dengan kisah 'berkah laut' dan bergerak untuk mengajarkan kekaguman pada alam semesta dan bagaimana menjaganya. 
Jadi mengajarkan ilmu tentang bencana, misal mengapa tsunami terjadi, tidak direkomendasikan, hal ini karena hanya akan menimbulkan ketakutan pada siswa. Pendekatan tersebut membedakan 'pendidikan melalui kesiapsiagaan bencana', berbeda dengan konsep 'pendidikan kesiapsiagaan bencana'. Pendidikan melalui kesiapsiagaan bencana atau model kyozon lebih mengutamakan penanaman pada siswa untuk menghargai hubungan antara manusia dengan alam saat menyadarkan akan bahaya bencana alam dan bukan sekedar menanamkan reaksi atas fenomena alam yang membahayakan. Studi ini menyimpulkan bahwa kesiapsiagaan bencana perlu diperluas melalui kerangka "keselamatan sekolah" sehingga menjadi 'bawaan' dalam kehidupan sehari-hari siswa, dengan demikian masyarakat di Jepang menyadari perlunya mengembangkan budaya 'kesiapsiagaan sehari-hari [seikatsu bosai]'.

Lebih luas dari keamanan terhadap bencana, otoritas pendidikan di Jepang, dalam hal ini Ministry of Education, Culture, Sports, Science and Technology's (MEXT), fokus pada 3 keselamatan sebagai salah satu tanggung jawabnya dalam mengedukasi warga negara Jepang, yaitu: 1) Everyday Safety, 2) Traffic Safety dan 3) Disaster Safety. Sementara Disaster Safety meliputi Disaster education, management dan coordinated activities. Secara sederhana sistem DE di Jepang dapat digambarkan melalui bagan berikut ini.

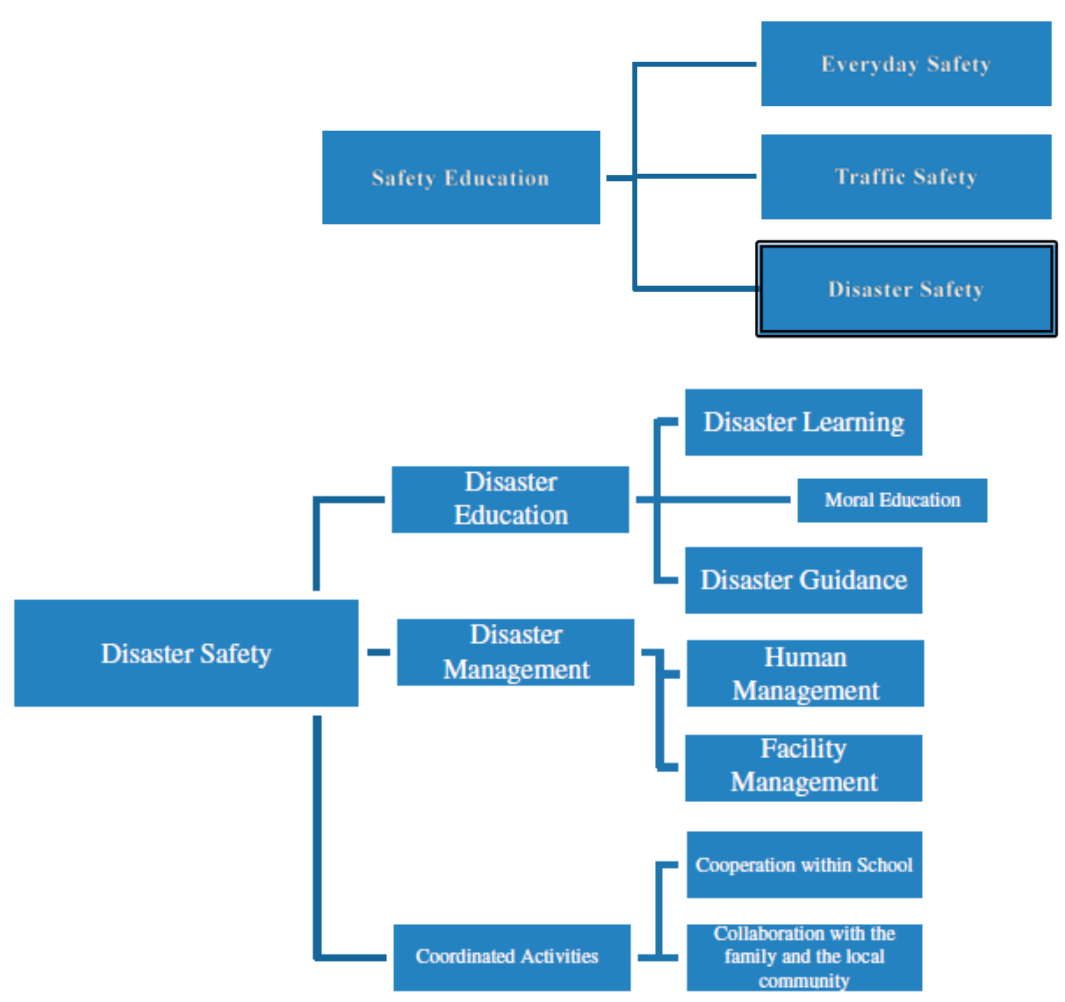

Gambar 1. Sistem Disaster Education (DE) di Jepang

Sumber: MEXT, Development of Disaster Education that Fosters 'Zest for Living' at School (Kitagawa, 2015) 


\section{c. Pendidikan Kebencanaan dan Problematika Implementasinya di Indonesia}

Sebagian kalangan pendidikan di Indonesia, khususnya sekolahsekolah di Indonesia telah mengenal pendidikan kebencaan. Terutama sekolah-sekolah yang berada pada daerah yang telah beberapa kali mengalami bencana besar, misal Aceh dengan bencana tsunami, Padang dengan bencana gempa bumi, Kediri dan Yogyakarta dengan bencana gunung berapi dan sebagainya. Pada daerah-daerah tersebut relatif mengenal pendidikan kebencaan, sebab baik dari pemerintah maupun non government organization $(\mathrm{NGO})$ telah memberikan sosialisasi bahkan melakukan implementasi pendidikan kebencanaan di berbagai sekolah di wilayah-wilayah tersebut. Namun demikian hal tersebut sifatnya masih insidental, setelah bencana dianggap selesai sampai rekonstruksi dan masyarakat telah kembali normal seperti sediakala maka program pendidikan kebencanaan pun ikut reda bahkan menghilang. Padahal potensi terjadinya kembali bencana tersebut terus membayangi wilayahwilayah tersebut. Untuk itu problematika mendasar adalah bukan pada pendidikan kebencanaan yang tidak ada di Indonesia, namun ada pada konsistensi dan terus menjadi perhatian semua pihak, baik pada saat sebelum bencana, saat terjadi bencana maupun setelah terjadi bencana. Singkatnya ada atau tidak ada kejadian bencana, pendidikan kebencanaan terus tetap berjalan. Sebab data menunjukkan wilayah Indonesia memiliki potensi tinggi akan terjadinya berbagai macam bencana alam.

Studi Kagawa dan Selby menghasilkan sebuah sintesis tentang Kurikulum Pendidikan Risiko Bencana
(PRB) di Indonesia sebagai berikut (Kagawa \& Selby, 2014):

- Pendidikan terdesentralisasi dan otonomi sistem pendidikan di Indonesia mendorong terjadinya prakarsa dan kebijakan pendidikan PRB yang beragam dan implementasinya diserahkan kepada masing-masing sekolah.

- Strategi pendidikan PRB nasional dan pedoman program sekolah aman merupakan dokumen yang saling menguatkan tetapi implementasi dan penguatan yang sistematis tetap menjadi tantangan di lapangan

- Sudah ada skema nasional yang aktif untuk pendidikan PRB di Indonesia dan program sekolah aman yang melibatkan lembaga pembangunan (NGO).

- Belum adanya kejelasan skema dalam hal pendidikan PRB di Indonesia apakah akan diintegrasikan dalam pembelajaran di kelas atau melalui ekstra-kurikuler atau pendidikan PRB berbasis masyarakat.

- Sekolah dan guru-guru di Indonesia sejauh ini belum memahami, memanfaatkan dan mengimplementasikan sepenuhnya kurikulum PRB untuk menangani bahaya dan kerentanan bencana alam di sekitarnya.

- Inisiatif pengembangan kurikulum PRB berbasis sekolah dalam skala kecil dengan waktu yang tidak berkala memang sudah ada misal melalui workshop, KKG/MGMP, namun peningkatan dan keberlanjutan tentang hal tersebut secara berlanjut masih menjadi tantangan bagi implementasi kurikulum PRB di Indonesia.

- Sama halnya di negara berkembang lainnya, di Indonesia tidak ada penyediaan pelatihan PRB bagi guru 
dalam jabatan maupun pra jabatan yang sistematis dan berlanjut.

Pada kurikulum terbaru di Indonesia yaitu Kurikulum 2013, sesungguhnya ada beberapa kompetensi di berbagai mata pelajaran yang mendorong (memfasilitasi) dan memberi peluang besar untuk terwujudnya proses pembelajaran yang mengintegrasikan pendidikan kebencanaan, misal:

1) Jenjang Sekolah Dasar, mata pelajaran Bahasa Indonesia (bahasa ) kelas $\mathrm{V}$ terdapat kompetensi Memiliki kepedulian, tanggung jawab, dan patriotisme terhadap bencana alam, keseimbangan ekosistem, dan kehidupan bangsa melalui pemanfaatan Bahasa Indonesia,

2) Jenjang SMP, mata pelajaran IPA kelas VIII terdapat kompetensi Memahami struktur bumi untuk menjelaskan gempa bumi dan fenomena vulkanik serta hubungannya dengan keanekaragaman batu dan mineral di beberapa daerah, Memberikan informasi berdasarkan data pemrosesan gempa bumi dan vulkanik fenomena di Indonesia

3) Jenjang SMTA / SMA Islam, mata pelajaran Geografi kelas X terdapat kompetensi Mengevaluasi tindakan yang mudah dalam mitigasi bencana alam.

Namun kembali lagi pada tantangan dan masalah utama yang telah diuraikan di atas, sehingga guru mampu dan mau atau tidak mengintegrasikannya dengan pendidikan kebencanaan atau otoritas pendidikan dan bagian kurikulum di sekolah mau mendorong atau tidak diimplementasikannya integrasi pendidikan kebencanaan dalam mata pelajaran. Selain hal tersebut belum ada sistem yang secara jelas menggambarkan peran dan tanggung jawab lembaga-lembaga yang terkait dengan pendidikan kebencanaan di Indonesia. Kementerian pendidikan dan kebudayaan, BNPB, BPBD, Basarnas dan sebagainya terkesan masih berjalan sendiri-sendiri dengan programnya masing-masing terkait dengan sosialisasi dan edukasi tentang resiko bencana dan upaya mengurangi resiko bahayanya pada masyarakat. Hal ini menyebabkan tidak adanya sistem pendidikan kebencanaan yang terstrutur, sistematis dan berkelanjutan, termasuk di sekolah-sekolah. Kementerian dan lembaga-lembaga terkait baru sebatas pada penyediaan dokumen-dokumen, namun sosialisasi dan implementasi di lapangan masih lemah dan tidak ada konsistensi yang berkelanjutan. Jika melihat kembali studi Kagawa dan Selby yang salah satunya mengungkapkan bahwa di Indonesia tidak ada penyediaan pelatihan PRB bagi guru dalam jabatan maupun pra jabatan yang sistematis dan berkelanjutan (Kagawa \& Selby, 2014), maka hal ini memang sesuai dengan kondisi yang ada sampai saat ini. Berdasarkan dokumen yang disusun Kementerian Pendidikan dan Kebudayaan dan BNPB paling tidak terdapat 4 dokumen rujukan dalam pendidikan kebencanaan di Indonesia yang diwujudkan dalam Program Sekolah Aman Bencana (Kemdikbud \& BNPB, 2016), yaitu:

1) Petunjuk teknis Bantuan Pemerintah dan Bantuan Sosial PRB di Direktorat Pembinaan PKLK;

2) Lembar Informasi Sekolah/Madrasah Aman Yang Komprehensif;

3) Pedoman Teknis penerapan SMAB di satuan pendidikan melalui program PRB di Direktorat Pembinaan PKLK; 
4) Roadmap Sekolah/Madrasah Aman, Kementerian Pendidikan dan

Kebudayaan 2015 - 2019.

Namun demikian isinya masih sebatas pada petunjuk pelaksaan bagi pelaksana kegiatan yang mayoritas berupa kegiatan pelatihan dan workshop yang harus dilakukan pada jenjang provinsi dan kabupaten/kota. Karena harus dibiayai oleh APBD maka program ini masih bersifat saran dan bukan menjadi kewajiban bagi daerahdaerah, sebab sangat tergantung pada kemampuan masing-masing daerah. Untuk itu problem anggaran menjadikan dokumen-dokumen pendidikan kebencanaan di Indonesia masih diimplementasikan secara insidental bahkan terkesan sekedar menjalankan kewajiban regulasi, belum menjadi sebuah kebutuhan dan kewajiban otoritas daerah untuk melindungi warga masyarakatnya. Maka pantas mayoritas guru-guru masih kebingungan mengimplementasikan dan mengintegrasikan pendidikan kebencanaan dalam muatan-muatan materi pelajaran yang sesungguhnya dekat dan erat kaitannya dengan pendidikan kebencanaan.

Hal-hal yang diuraikan di atas sejalan dengan studi lain tentang implementasi pendidikan kebencanaan di Indonesia yang dilakukan oleh Nurmahalayati Nurdin dkk. yang mengungkapkan bahwa tantangan implementasi pendidikan risiko benacana (PRB) di Indonesia diidentifikasi meliputi kapasitas guru yang terbatas, kurangnya pedoman praktis, terbatas dukungan keuangan dan kurangnya seperangkat kriteria dan pedoman untuk PRB (Nurdin, Rafliana, Hidayati, Oktari, \& Djalante, 2017). Selain itu masalah utama yang terjadi selama implementasi program adalah kurangnya pengetahuan guru tentang PRB. Meskipun kebutuhan untuk memasukkan PRB ke dalam kurikulum pendidikan Indonesia sudah jelas, namun tidak ada pedoman eksplisit tentang aspek "apa" atau "bagaimana", yang membuat proses implementasi menjadi kabur dan membingungkan guru. Bahkan tidak ada metrik penilaian yang jelas dan tolok ukur yang dapat mengukur apakah integrasi berhasil atau tidak. Temuan lainnya adalah tidak adanya kedudukan hukum untuk integrasi PRB ke dalam kurikulum yang menyebabkan implementasi tidak efektif. Kedudukan hukum Surat Edaran Menteri tentang integrasi PRB juga dianggap lemah. Sifat surat itu hanyalah 'saran' untuk memasukkan PRB ke dalam pendidikan, termasuk ke dalam kurikulum, tetapi tidak ada konsekuensi hukum jika sekolah tidak menerapkannya.

\section{d. Solusi Atas Problematika \\ Implementasi Pendidikan \\ Kebencanaan (Disaster Education) \\ di Indonesia}

Atas berbagai problematika implementasi pendidikan kebencanaan di Indonesia seperti yang telah diuraikan pada bagian sebelumnya, maka beberapa solusi berikut ini layak dipertimbangkan dan menjadi fokus perhatian semua pihak, terutama otoritas pemerintah Indonesia yang terkait dengan pendidikan dan kebencanaan, yaitu:

\section{1) Menata kembali sistem pendidikan kebencanaan yang jelas,
terstruktur dan sistematis}

Sistem pendidikan kebencanaan hendaknya ditata ulang agar menjadi sebuah sistem yang jelas, terstruktur dan sistematis mulai dari level pemerintahan pusat sampai sampai kabupaten/kota, bahkan sampai levelimplementasinya di sekolah-sekolah seperti halnya sistem disaster education di Jepang. Sistem 
pendidikan kebencanaan sudah saatnya diatur dalam regulasi yang lebih kuat tidak hanya sebatas pada peraturan menteri bahkan sebatas himbauan menteri seperti selama ini. Melihat data kejadian bencana alam yang semakin meningkat dengan jumlah korban jiwa dan material yang juga semakin besar, layak bahwa pendidikan kebencanaan ada pada level peraturan presiden atau instruksi presiden. Jika perlu menjadi salah satu pasal pada undang-undang pendidikan nasional. Hal ini sebagai bentuk tanggung jawab negara, dalam hal ini pemerintah untuk melindungi warga negaranya dengan cara preventif saat sebelum terjadi bencana, kesiapsiagaan saat terjadi bencana, tanggap serta bangkit kembali setelah terkena bencana alam. Pembentukan wawasan bahkan karakter ini membutuhkan waktu yang tidak sedikit dan pendidikan berperan besar dalam hal ini. Kesadaran membentuk warga negara yang siapsiaga sepanjang waktu telah dikembangkan bangsa Jepang sejak lama, sehingga setiap warga negaranya siap bahkan dianggap mampu hidup berdampingan dengan alam yang sewaktu-waktu dapat mengancamnya. Mampu hidup berdampingan dengan alam atau di bangsa Jepang dikenal dengan konsep Kyozon telah tertanam pada warga negaranya, dan melalui sistem pendidikan kebencanaan jelas, terstruktur dan sistematis lah pemerintah Jepang mampu menanamkan hal tersebut pada setiap warga negaranya.

\section{2) Menata kembali peran yang jelas dan tegas diantara kementerian dan lembaga-lembaga terkait dengan kebencanaan}

Lembaga-lembaga kementerian dan non kementerianyang terkait dengan pendidikan dan kebencanaan seperti kementerian pendidikan, BNPB, BPBD, Basarnas dan sebagainya, kedepan tidak hanya menjalankan fungsi saat terjadi bencana saja. Namun kedepan saling harus saling bersinergi dalam mengedukasi masyarakat tentang kesiapsiagaan mengahadapi bencana alam yang terjadi. Untuk jangka panjang, edukasi yang strategis adalah melalui pendidikan kebencanaan di sekolah-sekolah mulai dari jenjang usia dini sampai universitas. Jika sistem pendidikan kebencanaan yang jelas, terstruktur dan sistematis telah terwujud maka ada peran masing-masing lembaga tersebut dalam bersinergi seperti halnya sistem PRB di Selandia Baru.

\section{3) Menyusun kembali kurikulum kebencanaan (disaster curriculum)}

Muatan kurikulum yang ada saat ini belum menunjukkan kejelasan, sehingga guru kebingungan untuk mengimplementasikannya di kelas. Integrasi muatan kebencanaan pada materi masih kabur sehingga mayoritas guru mengabaikannya. Maka perlu dikaji ulang materi-materi kesiapsiagaan bencana untuk masuk dalam kurikulum pendidikan di Indonesia. Dengan demikian akan ada muatan kurikulum yang secara jelas dan tegas menyiapkan siswa untuk:

- memahami sains dan mekanisme bencana alam

- mempelajari dan mempraktikkan langkah-langkah dan prosedur keselamatan

- memahami faktor pendorong risiko dan bagaimana bahaya kecil dan sederhana dapat menjadi bencana

- membangun kapasitas pengurangan risiko masyarakat

- membangun budaya keselamatan dan ketahanan 
kelembagaan dan komunitas secara luas

\section{4) Melakukan sosialisasi dan edukasi sistem dan kurikulum pendidikan kebencanaan yang terstruktur, konsisten dan berkelanjutan.}

Persoalan mendasar bahwa pendidikan kebencanaan hanya bersifat insidental bahkan sekedar seremonial untuk launching program atau proyek. Untuk itu konsistensi dan keberlanjutan sosialisasi dan edukasi sistem dan kurikulum pendidikan kebencanaan harus tetap ada untuk seluruh guru-guru di seluruh wilayah Indonesia agar dapat mengintegrasikannya pada pembelajaran mereka. Ada bencana maupun tidak ada bencana, sosialiasasi dan edukasi harus tetap berjalan, sebab bencana alam tidak dapat diprediksi kapan terjadi. Manusia hanya bisa mempersiapkan diri untuk menghadapi sehingga mampu meminimalisir dampaknya. Maka perlu melakukan program masif dalam hal pendidikan kebencanaan kepada guru dalam jabatan maupun calon guru.

\section{KESIMPULAN}

Sebagai salah satu negara yang memiliki potensi kebencanaan yang cukup tinggi, Indonesia telah diperingatkan oleh berbagai pihak untuk segera membangun sistem kebencanaan secara menyeluruh termasuk mengintegrasikan kesiapsiagaan bencana ke dalam kurikulum pendidikannya. Namun demikian isu lingkungan dan kebencanaan yang seolah terus dibuktikan kebenarannnya oleh alam itu sendiri yaitu dengan semakin seringnya frekuensi terjadinya bencana alam, belum serta merta menggerakkan seluruh masyarakat untuk siapsiaga, termasuk masyarakat pendidikan. Kecenderungan mengabaikan data dan peristiwa kebencanaan masih menjadi masalah dan hambatan utama ketika kebijakan penanggulangan dampak bencana dari pemerintah pusat belum diimplementasikan secara menyeluruh dan bekelanjutan di masyarakat termasuk di sekolah-sekolah. Pelatihan dan pembimbingan implementasi kesiapsiagaan pada sekolah-sekolah yang oleh banyak negara lain dianggap jalur yang paling efektif untuk mengurangi dampak dan resiko bencana alam, masih belum maksimal diterapkan di Indonesia. Sekolah dan guru-guru masih belum jelas arah implementasi pendidikan kebencanaan di ruang kelas mereka masing-masing. Bahkan ketika Kurikulum 2013 terangterangan mencantumkan beberapa kompetensi yang erat kaitannya dengan kebencanaan sekalipun. Karena guruguru belum memahami esensi dan arah pendidikan kebencanaan maka kompetensi-kompetensi dalam kurikulum 2013 yang erat kaitannya dengan kebencanaan cenderung diabaikan muatan kebencanaannya. Berkaca dari negara Jepang, sejak usia dini warga negaranya ditanamkan dengan karakter bersahabat dengan alam, bahkan ketika alam mengandung potensi bencana alam sekalipun. Pada masyarakat Jepang bencana alam tidak lagi dianggap sebagai 'darurat' sehingga masyarakatnya harus "saling membantu (kyojo)" saja masyarakat Jepang ditanamkan sejak dini mengenal bencana alam dan menjadi keseharian mereka sehingga seluruh warganya harus mampu "hidup bersama (kyozon)" dengan bencana alam. Melihat letak geografis sebagai negara kepulauan dan tingginya potensi kebencanaan Indonesia yang tidak terlalu signifikan perbedaannya dengan Jepang, maka selayaknya Indonesia harus segera belajar. Agar masyarakat Indonesia tidak terus menerus menjadi masyarakat 
yang reaktif saat terjadi bencana namun menjadi masyarakat yang mengutamakan preventif akan bencana, dalam arti bukan melawan dan menghentikan bencana alam, namun telah siap siaga dalam berbagai hal dalam menghadapi bencana alam yang sewaktu-waktu mengancamnya, baik dalam hal material, infrastruktur dan terutama sikap dan perilakunya sebelum, saat terjadi dan sesudah bencana alam terjadi.

\section{DAFTAR PUSTAKA}

BNPB, I. (2017). Potensi dan Ancaman Bencana. Retrieved April 1, 2019, from Badan Nasional Penanggulangan Bencana website: https://bnpb.go.id

BNPB, I. (2019). Data Informasi Bencana Indonesia (DIBI). Retrieved April 1, 2019, from http://bnpb.cloud/dibi//tabel3a

Bündnis Entwicklung Hilft. (2018). The World Risk Report. Retrieved April 1, 2019, from WeltRisikoBericht website: https://weltrisikobericht.de/engli sh-2/

Chung, S.-C., \& Yen, C.-J. (2016). Disaster Prevention Literacy among School Administrators and Teachers: A Study on the Plan for Disaster Prevention and Campus Network Deployment and Experiment in Taiwan. Journal of Life Sciences, 10(4). https://doi.org/10.17265/19347391/2016.04.006

CNN, I. (2018, December 31). Pakar Luar Negeri Imbau Indonesia Lebih Sadar Potensi Bencana. Retrieved April 1, 2019, from internasional website: https://www.cnnindonesia.com/i nternasional/20181231144658106-357546/pakar-luar-negeri- imbau-indonesia-lebih-sadarpotensi-bencana

Heintze et.al, H.-J. (2018). World Risk Report 2018. Germany: Bündnis Entwicklung Hilft and Ruhr University Bochum.

Hyndman, D. W., \& Hyndman, D. (2017). Natural hazards and disasters (5th ed.). Boston, MA: Cengage Learning.

Kagawa, F., \& Selby, D. (2014). Disaster Risk Reduction In The School Curriculum, The Present And Potental Role Of Development Agencies And The Implications For The Hyogo Framework For Action 20052015 Successor. Journal of Education for Sustainable Development, 4(1), 131-133. https://doi.org/10.1177/0973408 20900400118

Kemdikbud, \& BNPB. (2016). Petunjuk Teknis Penerapan Sekolah Madrasah Aman Bencana (SMAB). Jakarta: Direktorat P2KLK.

Kitagawa, K. (2015). Continuity and change in disaster education in Japan. History of Education, 44(3), 371-390. https://doi.org/10.1080/0046760 X.2014.979255

Kitagawa, K., Preston, J., \& Chadderton, C. (2017). Preparing for disaster: a comparative analysis of education for critical infrastructure collapse. Journal of Risk Research, 20(11), 14501465.

https://doi.org/10.1080/1366987 7.2016.1178661

Kompas.com. (2018, October 9). Terkait Bencana, Ahli: Indonesia Tidak Punya "Safety Culture." Retrieved April 24, 2019 , 
https://properti.kompas.com/rea d/2018/10/09/190000621/terkait -bencana-ahli--indonesia-tidakpunya-safety-culture-

Musacchio, G., Falsaperla, S., Bernhardsdóttir, A. E., Ferreira, M. A., Sousa, M. L., Carvalho, A., \& Zonno, G. (2016). Education: Can a bottom-up strategy help for earthquake disaster prevention? Bulletin of Earthquake Engineering, 14(7), 2069-2086.

https://doi.org/10.1007/s10518015-9779-1

Nifa, F. A. A., Abbas, S. R., Lin, C. K., \& Othman, S. N. (2017). Developing a disaster education program for community safety and resilience: The preliminary phase.

020005. https://doi.org/10.1063/1.500533 8

Nurdin, N., Rafliana, I., Hidayati, S., Oktari, R. S., \& Djalante, R. (2017). Integrating Disaster Risk Reduction and Climate Change Adaptation into School Curricula: From National Policy to Local Implementation. In R. Djalante, M. Garschagen, F. Thomalla, \& R. Shaw (Eds.), Disaster Risk Reduction in Indonesia (pp. 213-234). https://doi.org/10.1007/978-3319-54466-3_8

Ronan, K. R., Alisic, E., Towers, B., Johnson, V. A., \& Johnston, D. M. (2015). Disaster Preparedness for Children and Families: a Critical Review. Current Psychiatry Reports, 17(7).

https://doi.org/10.1007/s11920015-0589-6

Shiwaku, K., Sakurai, A., \& Shaw, R. (2016). Disaster resilience of education systems: experiences from Japan (1st edition). New York, NY: Springer.

Winarni, E. W., \& Purwandari, E. P. (2018). Disaster Risk Reduction for Earthquake Using Mobile Learning Application to Improve the Students Understanding in Elementary School. Social Sciences, 9(2), 10. 